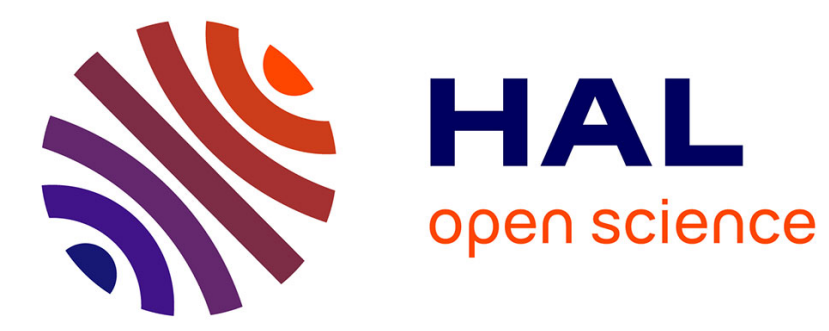

\title{
Chromium and iridium effects on the short-term interdiffusion behaviour between Pt rich $\gamma-\gamma$ ' bond-coatings and a Ni-Al-Cr alloy
}

Pauline Audigié, Aurélie Rouaix-Vande Put, Hideyuki Murakami, Daniel Monceau

\section{To cite this version:}

Pauline Audigié, Aurélie Rouaix-Vande Put, Hideyuki Murakami, Daniel Monceau. Chromium and iridium effects on the short-term interdiffusion behaviour between Pt rich $\gamma-\gamma$ ' bond-coatings and a NiAl-Cr alloy. Surface and Coatings Technology, 2017, 309, pp.258-265. 10.1016/j.surfcoat.2016.11.028 . hal-01585487

\section{HAL Id: hal-01585487 \\ https://hal.science/hal-01585487}

Submitted on 11 Sep 2017

HAL is a multi-disciplinary open access archive for the deposit and dissemination of scientific research documents, whether they are published or not. The documents may come from teaching and research institutions in France or abroad, or from public or private research centers.
L'archive ouverte pluridisciplinaire HAL, est destinée au dépôt et à la diffusion de documents scientifiques de niveau recherche, publiés ou non, émanant des établissements d'enseignement et de recherche français ou étrangers, des laboratoires publics ou privés. 


\section{Open Archive TOULOUSE Archive Ouverte (OATAO)}

OATAO is an open access repository that collects the work of Toulouse researchers and makes it freely available over the web where possible.

This is an author-deposited version published in : http://oatao.univ-toulouse.fr/ Eprints ID : 18104

To link to this article : DOI:10.1016/j.surfcoat.2016.11.028

URL : http://dx.doi.org/10.1016/j.surfcoat.2016.11.028

To cite this version : Audigié, Pauline and Rouaix-Vande Put, Aurélie and Murakami, Hideyuki and Monceau, Daniel Chromium and iridium effects on the short-term interdiffusion behaviour between Pt rich $\gamma-\gamma^{\prime}$ bond-coatings and a Ni-Al-Cr alloy. (2017) Surface and Coatings Technology, vol. 309. pp. 258-265. ISSN 0257-8972

Any correspondence concerning this service should be sent to the repository administrator: staff-oatao@listes-diff.inp-toulouse.fr 


\title{
Chromium and iridium effects on the short-term interdiffusion behaviour between Pt rich $\gamma-\gamma^{\prime}$ bond-coatings and a Ni-Al-Cr alloy
}

\author{
Pauline Audigié ${ }^{\mathrm{a}, 1}$, Aurélie Rouaix-Vande Put ${ }^{\mathrm{a}}$, Hideyuki Murakami ${ }^{\mathrm{b}}$, Daniel Monceau ${ }^{\mathrm{a}, *}$ \\ a Université de Toulouse, Institut Carnot Chimie Balard CIRIMAT, INPT-ENSIACET, 4 Allée Emile Monso, BP 44362, 31030 Toulouse Cedex 4, France \\ ${ }^{\mathrm{b}}$ National Institute for Materials Science (NIMS), Sengen 1-2-1, Tsukuba, Ibaraki 305-0047, Japan
}

Keywords:

Interdiffusion modelling

Bond-coatings

$\mathrm{Ni}-\mathrm{Al}-\mathrm{Cr}$ alloys

Platinum

Iridium

\begin{abstract}
A B S T R A C T
The interdiffusion behaviour of a $5 \mu \mathrm{m}$ thick layer of Pt deposited by electroplating on a $\gamma$-Ni-12Al-10Cr model alloy was studied in order to assess the effect of Cr. Heat treatments were performed for $1 \mathrm{~min}$ up to $1 \mathrm{~h}$ at $1100{ }^{\circ} \mathrm{C}$ under argon. $\mathrm{Cr}$ addition increased the uphill diffusion of $\mathrm{Al}$ to the surface when compared with $\mathrm{Pt} / \gamma$ $(\mathrm{Ni}, \mathrm{Al})$ systems. $\mathrm{Al}$ and $\mathrm{Cr}$ had a positive chemical interaction in presence of $\mathrm{Pt}$, as shown by the positive values of the $D_{A l C r}^{N i}$ and $D_{C r A l}^{N i}$ diffusion coefficients determined by modelling. Pt had a negative chemical interaction with $\mathrm{Al}$ and with $\mathrm{Cr}$ in such a way that Pt decreased their activities. According to the diffusion coefficient values, Pt had a greater influence on the Al activity than on the Cr one. Similarly, $2 \mu \mathrm{m}$ of Pt and $3 \mu \mathrm{m}$ of Pt-25Ir were deposited by electroplating on the same model alloy to investigate the effect of Ir. Heat treatments were performed in the same conditions as for $\mathrm{Cr}$. Iridium slowed down the interdiffusion when compared with systems with Pt only. Iridium diffused slower toward the substrate than Pt and a lower Pt + Ir flux toward the substrate was found. As voids formed at the interdiffusion zone/substrate interface due to Kirkendall effect, this lower inward $\mathrm{Pt}+\mathrm{Ir}$ flux resulted in a lower outward vacancy flux and then Ir reduced Kirkendall voids formation. Moreover, Ir decreased the Pt effect on Al activity by dilution or even gave an opposite contribution to the Pt one. This reduced the uphill diffusion of Al, delaying the $\alpha$-NiPtAl phase formation. Diffusion paths of each model system were also identified after $15 \mathrm{~min}$ at $1100{ }^{\circ} \mathrm{C}$ and all highlighted the $\alpha$-NiPtAl phase formation and its aptitude to be used in TBC systems.
\end{abstract}

\section{Introduction}

Thermal barrier coating systems (TBCs) are used to decrease the operating temperature of the underlying Ni-based superalloy in gas turbines [1]. Ni-based superalloys are used because of their mechanical properties at high temperature. They can be coated with Pt in order to enhance their corrosion and oxidation resistance. After a heat treatment under vacuum to inter-diffuse the Pt layer with the superalloy, an alumina-forming Pt-enriched $\gamma-\gamma^{\prime}$ bond-coating is formed [2-4]. The formation of this Al-rich coating is possible thanks to the decrease of $\mathrm{Al}$ chemical activity due to Pt, which allows Al diffusion against its composition gradient [3]. Full interpretation of the Pt effect is partly hindered by the effect of the other alloying elements. In that respect, the effect of Pt during fabrication was analysed in a preliminary study [5] by performing interdiffusion experiments at $1100{ }^{\circ} \mathrm{C}$ between a Pt coating and an $\mathrm{Al}-$ rich $\gamma$-Ni model alloy. In this previous work, the rapid formation and dissolution of the $\alpha$-NiPtAl phase was evidenced. Local phase transformations and diffusion paths were also demonstrated in the Ni-Al-Pt

\footnotetext{
* Corresponding author.

E-mail address: daniel.monceau@ensiacet.fr (D. Monceau).

1 Present address: Instituto Nacional de Técnica Aeroespacial INTA, Área de Materiales Metálicos, Ctra. Ajalvir Km 4, 28,850, Torrejón de Ardoz, SPAIN.
}

ternary system as $\gamma$-Pt $/ \alpha-\mathrm{NiPtAl} / \gamma^{\prime}-(\mathrm{Ni}, \mathrm{Pt})_{3} \mathrm{Al} / \gamma-(\mathrm{Ni}, \mathrm{Pt}, \mathrm{Al}) / \gamma-\mathrm{Ni} 13 \mathrm{Al}$. Finally, the deposition process was found not to be responsible for void formation, this latter being most likely due to the Kirkendall effect.

In order to go further and to approach the superalloy composition, $\mathrm{Cr}$ effect has to be studied. Used to strengthen the $\gamma$ matrix and to improve the corrosion resistance, $\mathrm{Cr}$ is the third main element of the first generation $\mathrm{Ni}$-based superalloys after $\mathrm{Ni}$ and $\mathrm{Al}[6,7]$. Despite its tendency to form brittle topologically-close-packed (TCP) phases [6-8], which decrease the strength of the material, $\mathrm{Cr}$ is beneficial for the hot corrosion resistance $[9,10]$. It also reduces the $\mathrm{Al}$ critical content necessary to sustain the growth of the alumina scale, this effect is known as the "thirdelement effect" [11,12]. In 1987, Nesbitt and Heckel reported that $\mathrm{Cr}$ has a positive chemical interaction with $\mathrm{Al}$ in the $\mathrm{Ni}-\mathrm{Al}-\mathrm{Cr}$ system [13]. In 2005, Hayashi et al. showed that the $\mathrm{Cr}$ concentration gradient is opposite to the one of Pt during interdiffusion in the Ni-Al-Cr/Ni-Al-Pt couple [14]. By increasing the $\mathrm{Al}$ activity due to this positive interaction, $\mathrm{Cr}$ would increase the Al flux toward the surface during the initial stages of interdiffusion. In addition to the assessment of diffusion coefficients in the Ni-Al-Cr-Pt quaternary system, the interest of this study was to analyse the $\mathrm{Cr}$ effect on the interdiffusion kinetics, more precisely on the uphill diffusion of Al. Therefore, the short-term interdiffusion behaviour at high temperature of an electroplated Pt coating with a $\gamma-\mathrm{Ni}(\mathrm{Al}, \mathrm{Cr})$ substrate was investigated in the present study. 


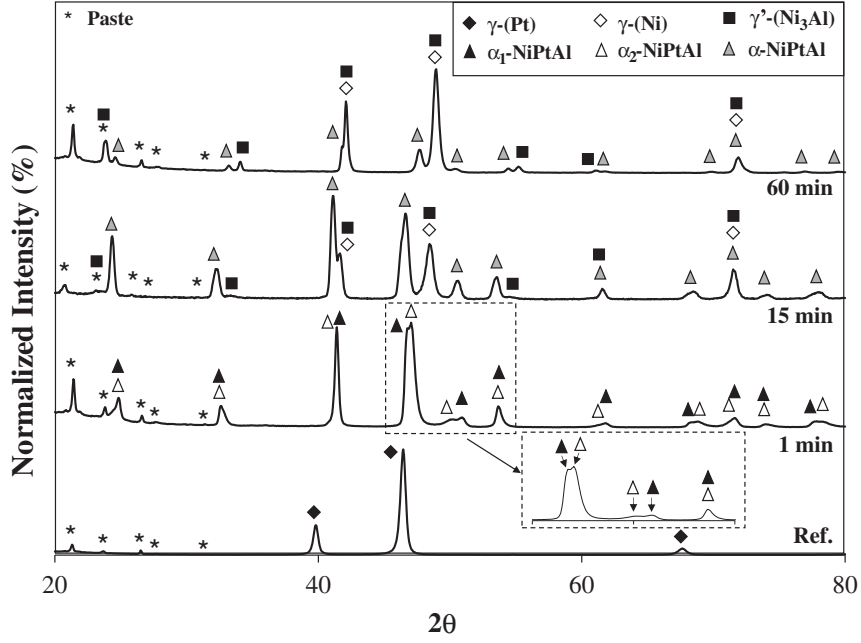

Fig. 1. X-ray diffraction patterns of the Ni-12Al- $10 \mathrm{Cr} / \mathrm{electroplated-Pt} \mathrm{system} \mathrm{after}$ fabrication (Ref.) and after $1 \mathrm{~min}, 15 \mathrm{~min}$ and $60 \mathrm{~min}$ at $1100{ }^{\circ} \mathrm{C}$ under argon.

Initially due to the Pt cost issue, a research group of the National Institute for Materials Science (NIMS, Japan) suggested to replace Pt-rich coatings by Ir-based bond-coatings [15,16], as it has been tested for Pd before [17-21]. Iridium has the second highest melting point (2716 K) amongst the Pt group metals. It also has an excellent chemical stability, low oxygen diffusivity [22] and a higher mechanical strength than Pt [23]. Contrary to Pt, Ir preferentially partitions in the $\gamma$ phase instead of in the $\gamma^{\prime}$ phase $[24,25]$. It has been also mentioned that Ir delays the outward diffusion of the superalloy refractory elements $[15,26]$ and can prevent the formation of Kirkendall voids in the substrate [27]. In order to determine the influence of this element on the interdiffusion behaviour, model systems consisting of Pt and Ir coatings deposited on the $\gamma-\mathrm{Ni}(\mathrm{Al}, \mathrm{Cr})$ ternary alloy were also examined.

\section{Materials and experiments}

A rod of polycrystalline $\mathrm{Ni}-13 \mathrm{Al}-10 \mathrm{Cr}$ (at.\%) alloy was prepared by vacuum arc melting from high-purity $\mathrm{Ni}, \mathrm{Al}$ and $\mathrm{Cr}$ at the NIMS and was subsequently annealed for $1 \mathrm{~h}$ at $1100{ }^{\circ} \mathrm{C}$ in air. After heat treatment, the rod was quenched into air in order to preserve its high temperature $\gamma$ microstructure and avoid the $\gamma^{\prime}$ precipitation. After heat treatment, the alloy average grain size was $245 \mu \mathrm{m}$. The as-cast alloy mean composition was $\mathrm{Ni}-11.6 \mathrm{Al}-10.3 \mathrm{Cr}$ (at.\%), according to electron probe microanalysis (EPMA), indicating a slightly lower Al content than expected. This alloy will be named $\mathrm{Ni}-12 \mathrm{Al}-10 \mathrm{Cr}$ throughout the rest of the article. Samples of $25 \mathrm{~mm}$ diameter and 1.5 to $2 \mathrm{~mm}$ thickness were cut, polished with $\mathrm{SiC}$ paper down to grade \#400, cleaned with ethanol in an ultrasonic bath and grit-blasted with $\alpha-\mathrm{Al}_{2} \mathrm{O}_{3}$ particles. A pure Pt coating, $5 \mu \mathrm{m}$ thick, was deposited on the substrate by electroplating using the facilities of the NIMS [16]. Then, samples were sealed into quartz capsules under an argon atmosphere. After a rapid heating $\left(\sim 200{ }^{\circ} \mathrm{C} / \mathrm{min}\right)$, heat treatments of $1 \mathrm{~min}, 15 \mathrm{~min}$ and $1 \mathrm{~h}$ dwell at $1100{ }^{\circ} \mathrm{C}$ were performed and cooling of quartz capsules was done under laboratory air.

In order to study the Ir effect, some samples of $\mathrm{Ni}-12 \mathrm{Al}-10 \mathrm{Cr}$ were coated with a $2 \mu \mathrm{m}$ thick Pt layer and a $3 \mu \mathrm{m}$ thick Pt-25Ir (at.\%) layer by electroplating. Before deposition, the surface was grit-blasted with $\alpha-\mathrm{Al}_{2} \mathrm{O}_{3}$ particles in order to increase the coating adhesion, followed by the degreasing procedure. Then, samples were sealed into quartz capsules and heat-treated at $1100^{\circ} \mathrm{C}$ under argon using the same procedure than samples with the Pt coating.

For both coatings (Pt with/without Ir), X-ray diffraction (XRD) analyses were performed at room temperature after heat treatment (20$80^{\circ}$, with a $0.5^{\circ}$ step and a $2 \mathrm{~s}$ holding-time). Lattice parameters were determined from the three main peaks of each phase ((001), (110) and (111) for the $\alpha$-NiPtAl phase, (111), (200) and (220) for the $\gamma$ $(\mathrm{Ni}, \mathrm{Pt}, \mathrm{Al})$ and $\gamma^{\prime}-(\mathrm{Ni}, \mathrm{Pt})_{3} \mathrm{Al}$ phases) using CaRIne Crystallography software. After interdiffusion, sample cross-sections were prepared and analysed by scanning electron microscopy (SEM). Electron-probe microanalysis was performed to determine the quantitative concentration profile of each element. In addition, the interdiffusion zone thickness of
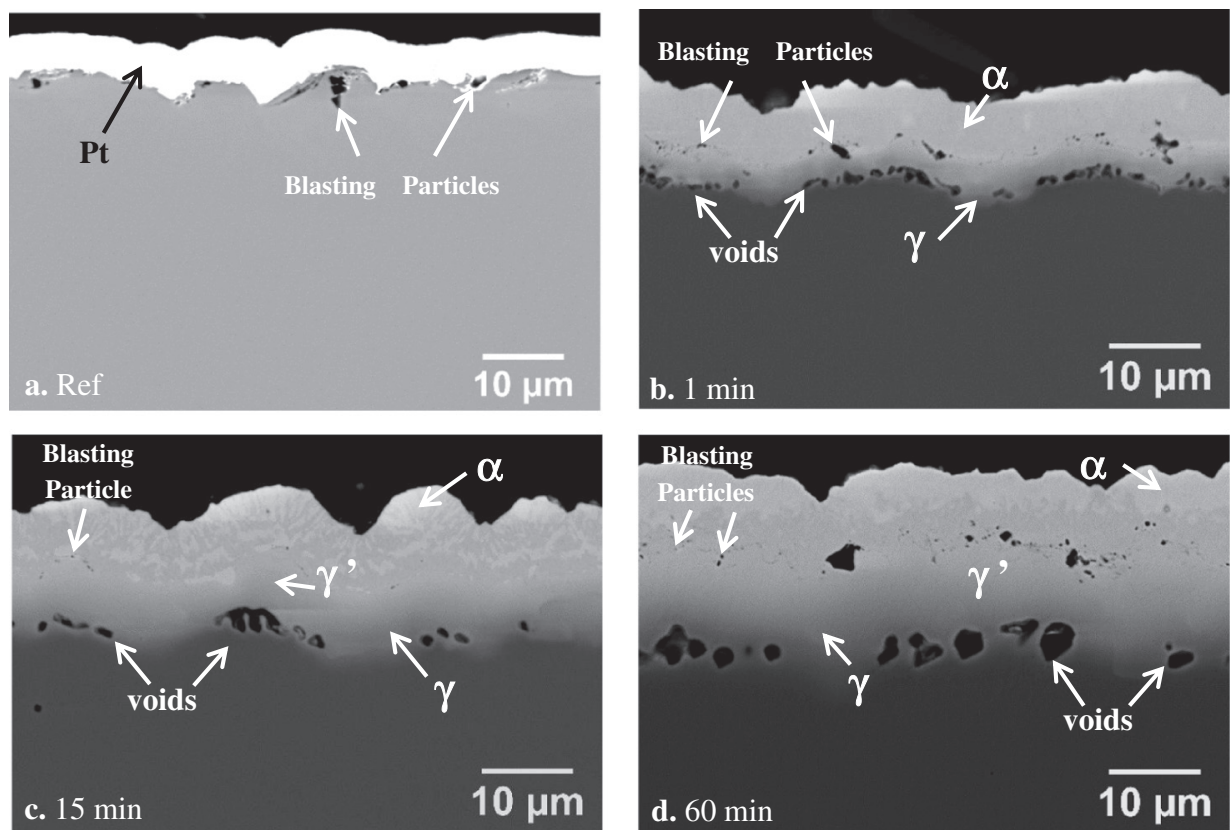

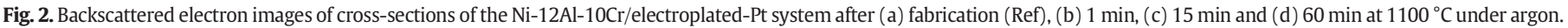



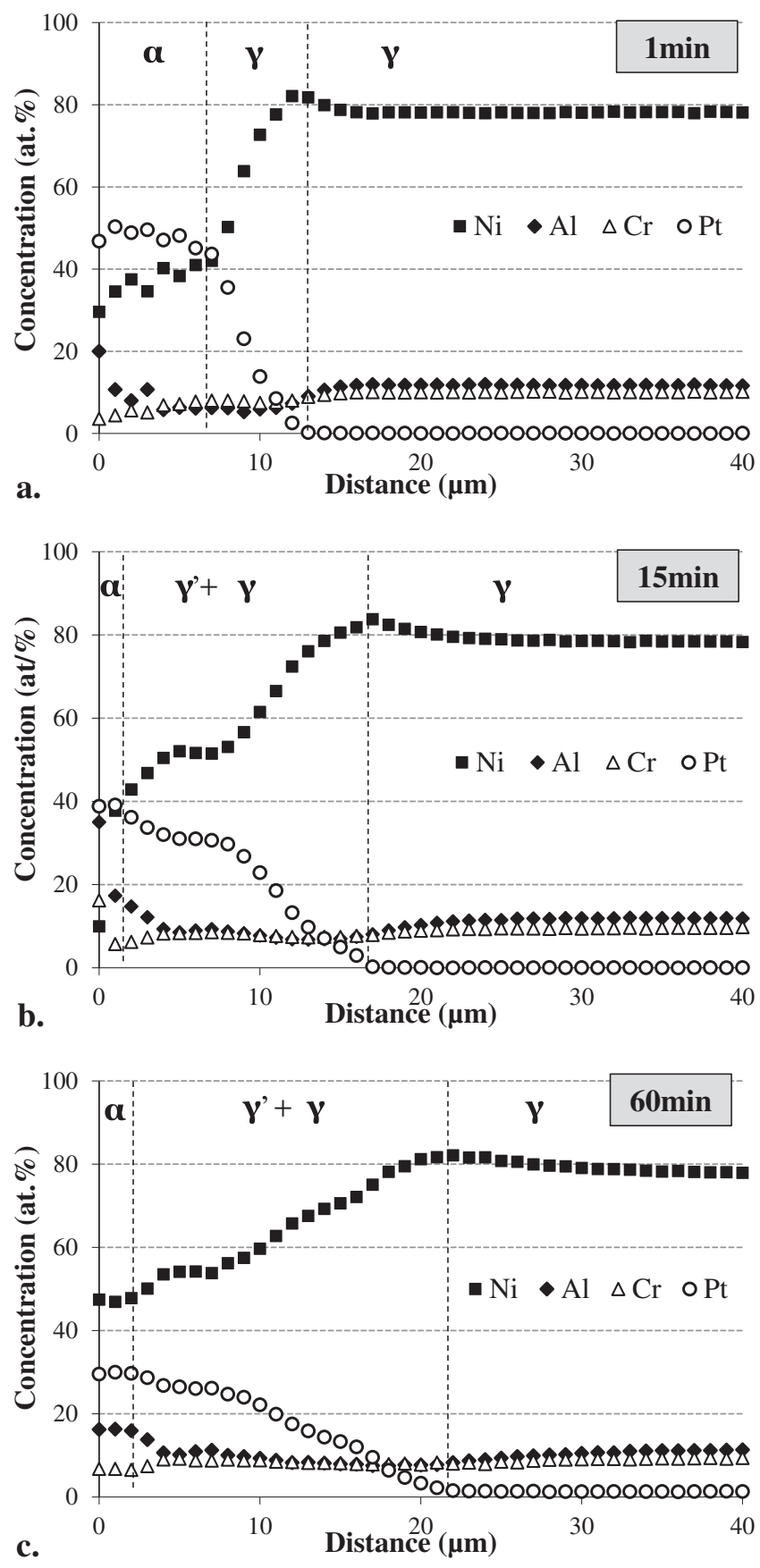

Fig. 3. EPMA concentration profiles ( 1 point every $1 \mu \mathrm{m}$ ) for the $\mathrm{Ni}-12 \mathrm{Al}-10 \mathrm{Cr} /$ electroplated-Pt system after (a) $1 \mathrm{~min}$, (b) $15 \mathrm{~min}$ and (c) $60 \mathrm{~min}$ at $1100{ }^{\circ} \mathrm{C}$ under argon.

each system was measured in order to analyse the global diffusion kinetics. Three areas per sample were observed and five values per area were measured, being a total of 15 measures per sample. In this work, the interdiffusion zone (IZ) was defined as the zone between the original interface identified by the $\mathrm{Al}_{2} \mathrm{O}_{3}$ grit particles and the platinum or platinum-iridium diffusion front.

Furthermore, a computer program using an explicit finite difference (FD) scheme was used to calculate the fluxes and the concentration profiles in the $\gamma \mathrm{Ni}$-Al-Cr-Pt system. The fluxes were written as generalized Fick's laws using cross-term diffusion coefficients. More details about the model are given in a previous publication [5].
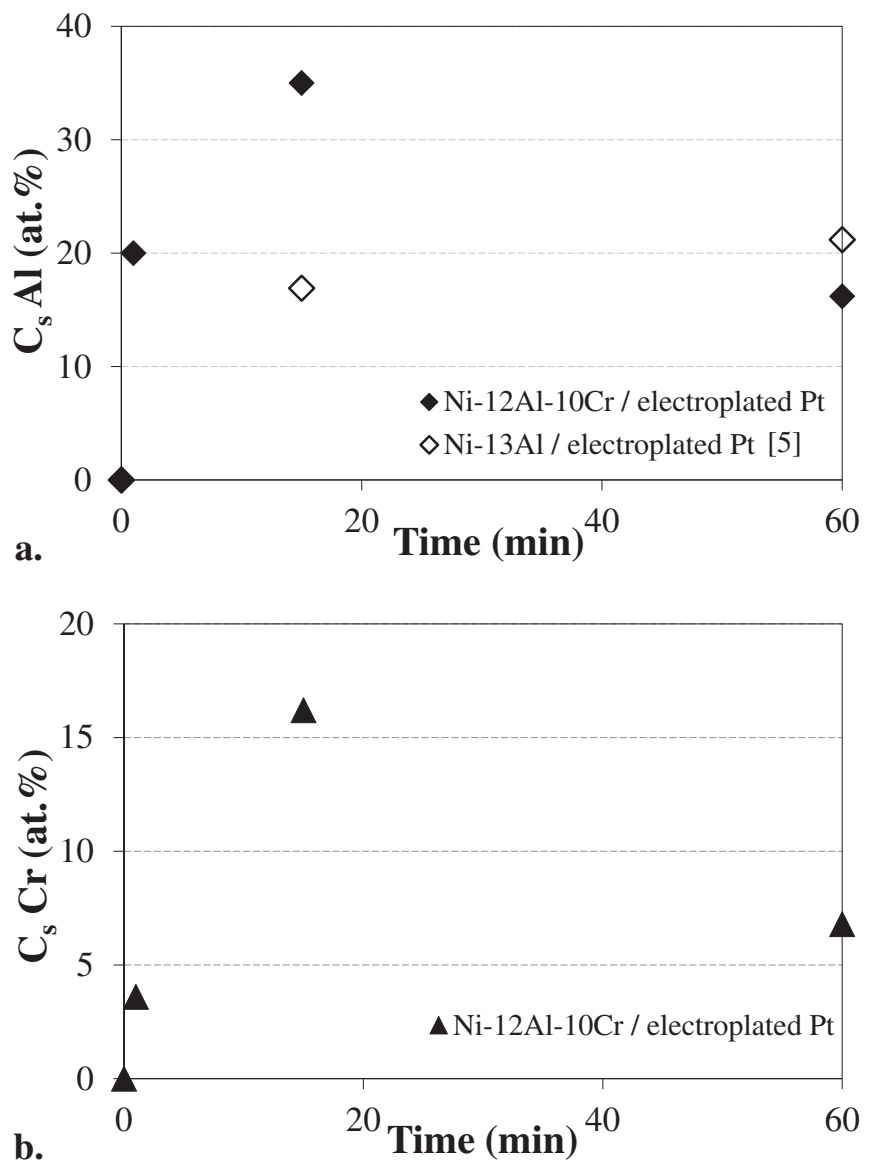

Fig. 4. (a) Aluminum and (b) chromium surface concentration versus annealing time at $1100{ }^{\circ} \mathrm{C}$ for the $\mathrm{Ni}-13 \mathrm{Al} /$ electroplated Pt and Ni-12Al-10Cr/electroplated Pt systems.

\section{Results and discussion}

\subsection{Chromium effect}

Fig. 1 and Fig. 2 exhibit X-ray diffraction patterns and backscattered electron (BSE) images of cross-sections of the $\mathrm{Ni}-12 \mathrm{Al}-10 \mathrm{Cr} /$ electroplated-Pt system annealed $1 \mathrm{~min}, 15 \mathrm{~min}$ and $60 \mathrm{~min}$ at $1100{ }^{\circ} \mathrm{C}$ under argon. Similar phases than the ones of the Ni-Al-Pt ternary system [5] were observed whatever the duration of the heat treatment was.

After $1 \mathrm{~min}$, the subsurface bond-coating was mainly composed of the $\alpha$-NiPtAl phase with the $\mathrm{L} 1_{0}$ structure. Two occurrences of the $\alpha$ phase were identified by XRD at room temperature. They are called $\alpha_{1}$ and $\alpha_{2}$ on the diffraction patterns. The lattice parameter "a" of the two phases was similar $\left(0.3878 \mathrm{~nm}\right.$ and $0.3865 \mathrm{~nm}$ for $\alpha_{1}$ and $\alpha_{2}$ respectively) whereas their lattice parameter "c" differed $(0.3586 \mathrm{~nm}$ and $0.3635 \mathrm{~nm}$ for $\alpha_{1}$ and $\alpha_{2}$ respectively). As reported in the Ni-Al-Pt system, $\alpha$-NiPtAl formation was caused by the rapid diffusion toward the surface of $\mathrm{Ni}$ and $\mathrm{Al}[5,28]$, the uphill $\mathrm{Al}$ diffusion being favoured by the decrease in $\mathrm{Al}$ activity due to $\mathrm{Pt}$ [3].

Additional phase transformations occurred when the annealing time increased. After $15 \mathrm{~min}$ at $1100{ }^{\circ} \mathrm{C}$, the $\alpha$-NiPtAl phase was still present and preferentially oriented along the (100) direction perpendicular to the surface. Simultaneously, the $\gamma^{\prime}-(\mathrm{Ni}, \mathrm{Pt})_{3} \mathrm{Al}$ and the $\gamma$-Ni(Al,Cr,Pt) phases appeared, and were characterized by a lattice parameter of $0.3795 \mathrm{~nm}$ and $0.3752 \mathrm{~nm}$ respectively. The ternary equilibrium, which was not observed in the isothermal and isobaric ternary systems in agreement with the Gibbs rule, was not observed in systems containing Cr. After $60 \mathrm{~min}$ at $1100^{\circ} \mathrm{C}, \alpha$-NiPtAl and $\gamma^{\prime}$-(Ni,Pt) $)_{3} \mathrm{Al}$ were still observed. But $\alpha$-peak intensities decreased whereas the ones of $\gamma^{\prime}$ increased. 

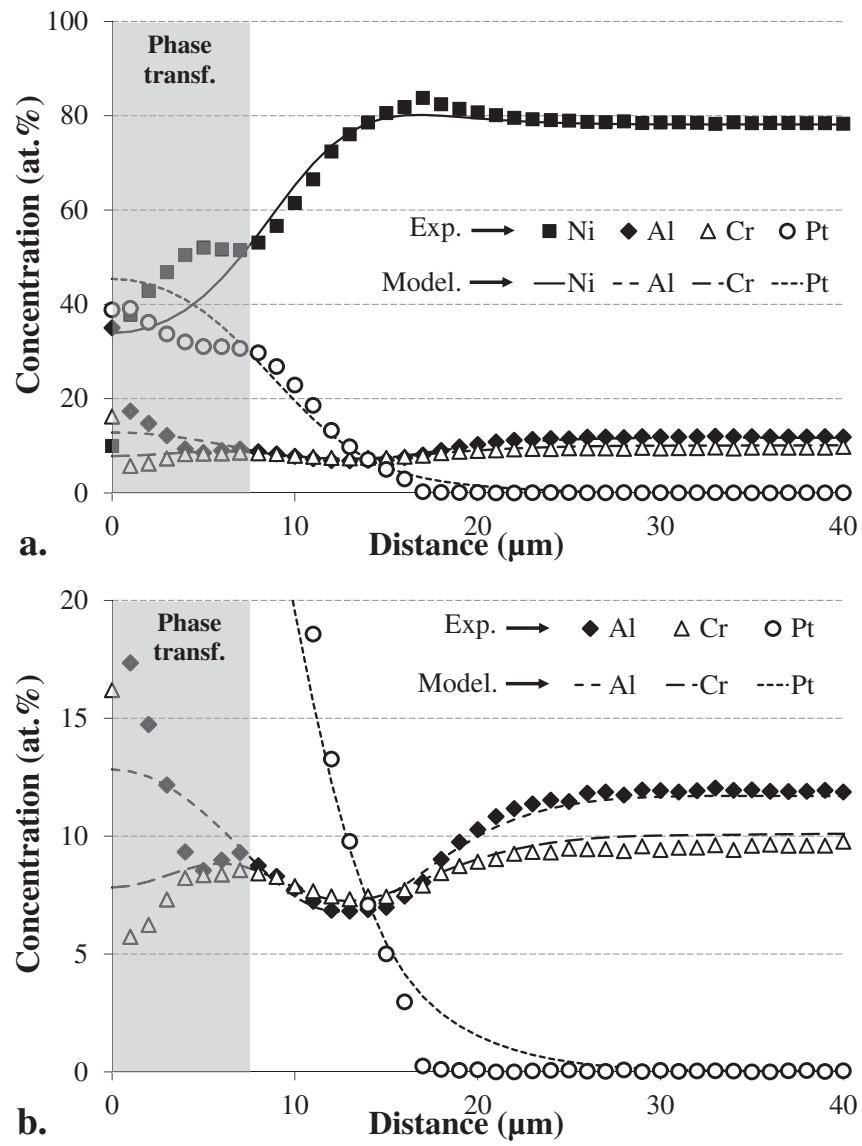

Fig. 5. Comparison between experimental profiles (symbols) and calculated profiles (lines) for the Ni-12Al-10Cr/electroplated-Pt system after $15 \mathrm{~min}$ at $1100{ }^{\circ} \mathrm{C}$ under argon. Figure (b) is an enlargement of Figure (a).

SEM observations after 1,15 and $60 \mathrm{~min}$ at $1100^{\circ} \mathrm{C}$ are shown in the Fig. 2. The surface undulations correspond to the "cauliflower"-shaped Pt grains obtained after electroplating. $\alpha-\mathrm{Al}_{2} \mathrm{O}_{3}$ particles from the gritblasting process mark the initial interface between the Pt coating and the $\gamma$ alloy. The SEM-BSE observations confirmed the presence of three phases. The brighter (i.e. heavier) phase was $\alpha$-NiPtAl due to its higher Pt content, the darker phase was $\gamma-\mathrm{Ni}(\mathrm{Al}, \mathrm{Cr}, \mathrm{Pt})$. For each annealing time, the cross-section microstructure can be divided into three zones: the Pt-rich zone above the initial surface, the interdiffusion zone whose thickness increased with time, and the base material. After $1 \mathrm{~min}$ at $1100{ }^{\circ} \mathrm{C}$, a continuous subsurface $\alpha$ layer with a thickness of $6 \mu \mathrm{m}$ was observed (the two $\alpha$ phases detected by XRD were not distinguished by SEM). After $15 \mathrm{~min}$, the subsurface zone mainly transformed into $\gamma^{\prime}-(\mathrm{Ni}, \mathrm{Pt})_{3} \mathrm{Al}$ and a thin layer of $\alpha$ phase was observed below the surface. After $60 \mathrm{~min}$, the same microstructure was observed but the $\alpha$-layer average thickness decreased down to $1.6 \mu \mathrm{m}$ (Fig. $2 \mathrm{~d}$ ). EPMA analyses confirmed the phase identification and the thickness variations of the different layers (Fig. 3). Voids also formed at the interdiffusion zone/substrate interface whatever the annealing time as shown in Fig. 2.

Table 1

Diffusion coefficients $D_{i j}^{N i}\left(\mathrm{~m}^{2} / \mathrm{s}\right)$ at $1100{ }^{\circ} \mathrm{C}$ used for the FD modelling in the Ni-Al-Cr-Pt system presented in Fig. 5.

\begin{tabular}{llll}
\hline $\mathrm{i} \backslash \mathrm{j}$ & $\mathrm{Al}$ & $\mathrm{Cr}$ & $\mathrm{Pt}$ \\
\hline $\mathrm{Al}$ & $1.8 \times 10^{-14}$ & $7.5 \times 10^{-15}$ & $-7.5 \times 10^{-15}$ \\
$\mathrm{Cr}$ & $5.0 \times 10^{-15}$ & $1.2 \times 10^{-14}$ & $-4.7 \times 10^{-15}$ \\
$\mathrm{Pt}$ & $-9.5 \times 10^{-15}$ & $-5.0 \times 10^{-15}$ & $1.3 \times 10^{-14}$ \\
\hline
\end{tabular}

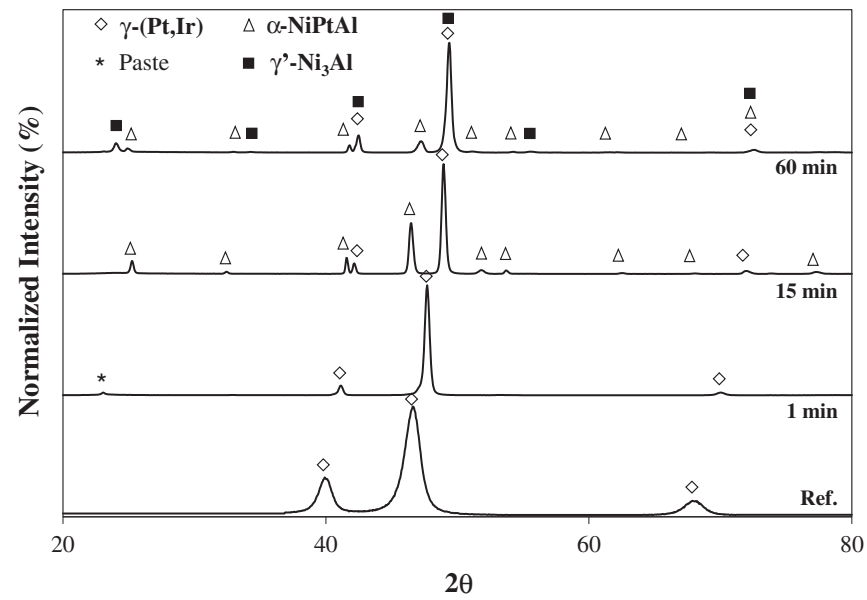

Fig. 6. X-ray diffraction patterns of the Ni-12Al-10Cr/Pt + Pt-25Ir (at.\%) system after fabrication (Ref) and after $1 \mathrm{~min}, 15 \mathrm{~min}$ and $60 \mathrm{~min}$ at $1100{ }^{\circ} \mathrm{C}$ under argon.

According to statistical analysis made on the Ni-Al-Pt system from the previous study [5] and on the Ni-Al-Cr-Pt system based on 15 measures for each point, the interdiffusion zone thicknesses were slightly smaller in the quaternary system than in the ternary system. For example, the interdiffusion zone thickness of the Ni-Al-Pt system after $15 \mathrm{~min}$ was $9.1 \pm 1.1 \mu \mathrm{m}$ whereas the one of the system containing $\mathrm{Cr}$ was $7.9 \pm 1.0 \mu \mathrm{m}$. However, smaller interdiffusion zone growth kinetics in presence of $\mathrm{Cr}$ does not mean that $\mathrm{Cr}$ slowed down the interdiffusion. The diffusion coefficients determined from the modelling and discussed later will clarify this point.

To better understand the $\mathrm{Cr}$ effect on the Al diffusion, the Al surface concentration was plotted versus the annealing time for each model system (Fig. 4.a) [5,29]. A higher uphill Al diffusion was observed for the Ni-12Al-10Cr/electroplated-Pt with an Al surface concentration of 34 at.\% after $15 \mathrm{~min}$. $\mathrm{Cr}$ has a positive chemical interaction with $\mathrm{Al}$ in $\mathrm{Ni}-\mathrm{Cr}-\mathrm{Al}$ systems [13] and increases the Al activity in the substrate. In that point of view, Al diffuses uphill faster in $\mathrm{Cr}$-rich systems because the $\mathrm{Cr}$ concentration gradient was opposite to the one of Pt in Ni-AlCr-Pt systems [14]. The present observations are in accordance with these previous studies [13,14]. Moreover, the EPMA Cr concentration profiles showed a small peak at around $5 \mu \mathrm{m}$ below the surface (Fig. 3 ). This depth corresponded to the initial interface between the Ptrich zone and the interdiffusion zone.

The $\mathrm{Cr}$ surface concentration was plotted versus the annealing time (Fig. 4.b). Cr surface concentration in the Ni-12Al-10Cr/electroplated-Pt system was superior to the one in the substrate after 15 min at $1100{ }^{\circ} \mathrm{C}$ (16.2 at.\% at the surface against 10.1 at.\% in the bulk). $\mathrm{Cr}$ can diffuse uphill toward the surface due to a chemical interaction with another chemical element. Similarly to what happened between $\mathrm{Al}$ and Pt, it can be supposed that Pt decreased the $\mathrm{Cr}$ activity and favoured its diffusion toward the surface.

Computer simulations were used to reproduce the composition profile evolution in the single phased $\mathrm{Ni}-\mathrm{Al}-\mathrm{Cr}$-Pt system. The diffusion coefficients were determined by using the ones of the ternary Ni-Al-Pt system as initial starting points [5] and by proceeding by trial and error method. Fig. 5 compares experimental and calculated profiles for the Ni-12Al-10Cr/electroplated-Pt system after $15 \mathrm{~min}$ at $1100{ }^{\circ} \mathrm{C}$ under argon. The $\mathrm{Ni}, \mathrm{Al}, \mathrm{Cr}$ and $\mathrm{Pt}$ concentration profiles after $1 \mathrm{~min}$ at $1100{ }^{\circ} \mathrm{C}$ were considered as the initial conditions. Experimental and calculated profiles were found to be in reasonable agreement for the $\gamma$-phased systems, excepted below the surface where phase transformations occurred. In addition, the expected uphill Al diffusion and the "S-shape" of the $\mathrm{Cr}$ profile were predicted by the model. The fitted interdiffusion coefficients at $1100{ }^{\circ} \mathrm{C}$ in the Cr-rich system (Table 1) were ten times higher $\left(\sim 10^{-14} \mathrm{~m}^{2} / \mathrm{s}\right)$ than the ones reported in the 

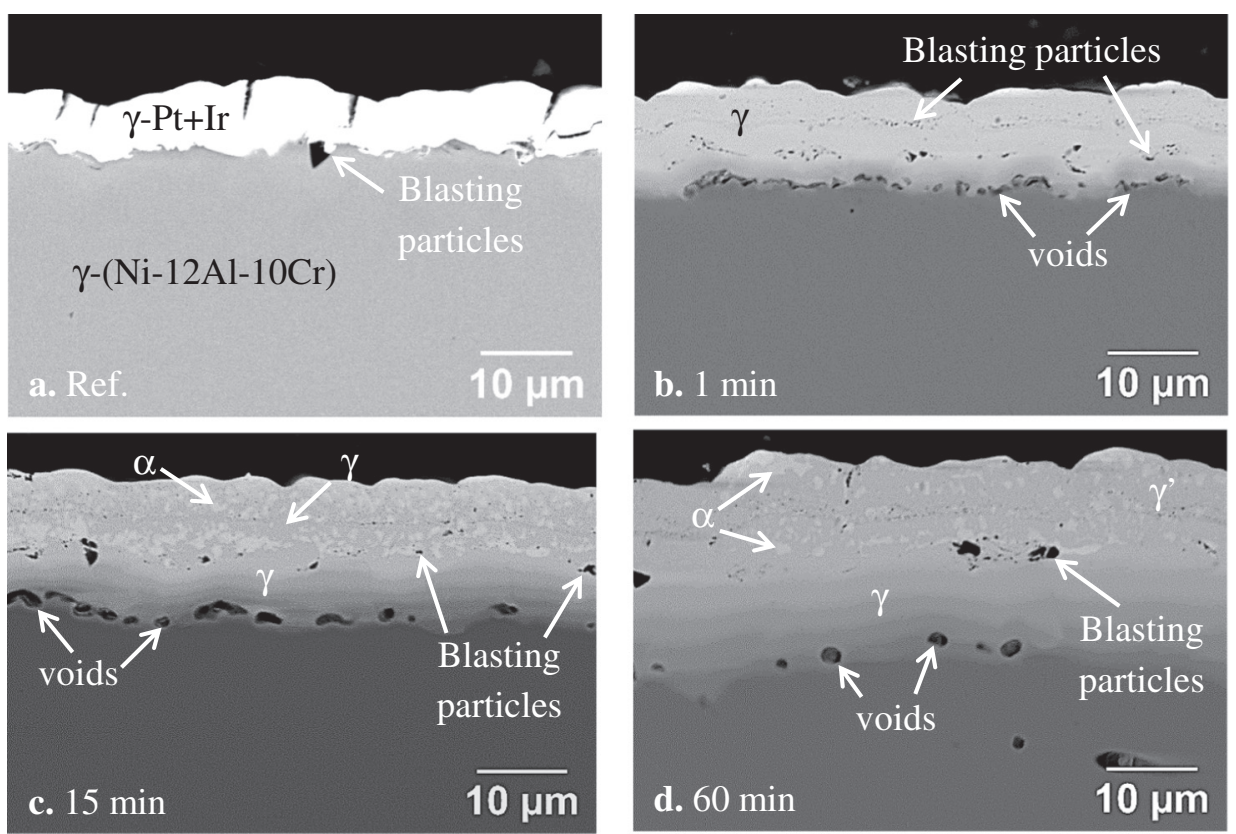

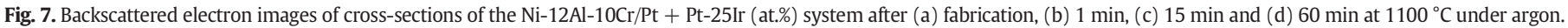

literature for the $\gamma$-Ni phase and in the Ni-Al-Pt systems [30,31] $\left(\sim 10^{-15} \mathrm{~m}^{2} / \mathrm{s}\right)$. As listed in Table 1 , all the main-term matrix coefficients are positive and ten times higher than the cross-term matrix coefficients in absolute value, as observed by Nesbitt and Heckel in Ni-Cr-Al alloys [32]. $D_{A I P t}^{N i}$ and $D_{P t A l}^{N i}$ are negative which is consistent with Gleeson's study [3] about the Pt thermodynamic effect on the Al activity. $D_{A l C r}^{N i}$ and $D_{C r A l}^{N i}$ are positive proving that the chemical interaction between $\mathrm{Al}$ and $\mathrm{Cr}$ is positive in systems containing $\mathrm{Pt}$ as it was shown in systems without Pt $[13,33]$. This also confirmed that the $\mathrm{Cr}$ effect on the $\mathrm{Al}$ activity is contrary to the one of Pt. Then, the modelling evidenced a negative interaction between $\mathrm{Cr}$ and $\mathrm{Pt}$. A negative value was obtained for the cross-term diffusion coefficient $D_{C r P t}^{N i}$ implying that $D_{C r P t}$ was negative and that $\mathrm{Pt}$ decreases the $\mathrm{Cr}$ activity. According to the diffusion coefficient values $D_{C r P t}^{N i}=-4.7 \times 10^{-15} \mathrm{~m}^{2} / \mathrm{s}$ and $D_{A l P t}^{N i}=-7.5 \times 10^{-15-}$ $\mathrm{m}^{2} / \mathrm{s}$, Pt would have a greater influence on the Al activity than on the $\mathrm{Cr}$ one. This can be explained by the fact that Pt partitions preferentially in the $\gamma^{\prime}$ phase like $\mathrm{Al}$ whereas $\mathrm{Cr}$ partitions preferentially in the $\gamma$ phase. A first approximation of the $\mathrm{Cr}$ partitioning coefficient $\gamma / \alpha$ equal to 1.4 also confirmed that $\mathrm{Cr}$ diffuses uphill toward the surface due to its interaction with Pt and not due to the $\alpha$ phase formation. Therefore, $\mathrm{Cr}$ enhanced interdiffusion although the interdiffusion zone thicknesses were found to be thinner in the $\mathrm{Cr}$-containing system than the $\mathrm{Cr}$-free one. The main-term diffusion coefficients were ten times higher than the ones of $\gamma$-Ni and Ni-Pt-Al systems [5]. These greater main-term diffusion coefficients were compensated by larger negative cross-term diffusion coefficients in absolute value.

\subsection{Iridium effect}

Fig. 6 and Fig. 7 show the X-ray diffraction patterns and the crosssection backscattered electron images of the Ni-12Al-10Cr/Pt $+\mathrm{Pt}-$ 25Ir system after fabrication and after $1 \mathrm{~min}, 15 \mathrm{~min}$ and $60 \mathrm{~min}$ at $1100{ }^{\circ} \mathrm{C}$ under argon. After fabrication, the bond-coating was $\gamma$ single phase with a lattice parameter equal to $0.3895 \mathrm{~nm}$ which lies between the cell parameter of pure Pt $(0.3920 \mathrm{~nm})$ and the one of pure Ir $(0.3840 \mathrm{~nm})$. This value was consistent with the Vegard's law which gives a lattice parameter of $0.3900 \mathrm{~nm}$ for a Pt-25Ir (at.\%) bulk material. The coating was fully-adherent to the substrate, based on a scratch test. After $1 \mathrm{~min}$, the XRD analyses revealed that one $\gamma$ phase was identified with a lattice parameter of $0.3800 \mathrm{~nm}$ at room temperature (Fig. 6).
However, SEM observations showed a multi-layered system with various thicknesses (Fig. 7b). The grit blasting particles which appeared in black in backscattered electrons mode marked the interface positions compared to the initial interface. The microstructure can be divided into four zones from the surface to the core: a $3.4 \mu \mathrm{m}$ thick Pt- and Irrich zone, a $2.4 \mu \mathrm{m}$ thick Pt-rich zone, a $4.6 \mu \mathrm{m}$ thick interdiffusion zone and the base material (Fig. 8.a). After $15 \mathrm{~min}$, the $\alpha$-NiPtAl phase appeared and was characterized by lattice parameters equal to $\mathrm{a}=$ $0.3900 \mathrm{~nm}$ and $\mathrm{c}=0.3515 \mathrm{~nm}$ at room temperature. The small $\alpha$-NiPtAl precipitates were at the thermodynamic equilibrium with the $\gamma$-(Pt,Ir) matrix whose lattice parameter decreased because of the composition variation. The precipitates being the brightest phase, they were observed in the two subsurface layers but not in the interdiffusion zone. They eventually formed during cooling because of their small size. The interdiffusion zone thickness increased and measured $7.3 \pm 0.8 \mu \mathrm{m}$ in average. This value was similar to the one of systems without Ir ( $7.9 \pm 1.0 \mu \mathrm{m}$ after the same duration). After the longer heat treatment (60 min), three phases were detected by XRD. The $\alpha$-NiPtAl was identified with lattice parameters $\mathrm{a}=0.3840 \mathrm{~nm}$ and $\mathrm{c}=0.3560 \mathrm{~nm}$ although the peak intensities decreased when compared to the heat treatment of $1 \mathrm{~min}$. Its disappearance seemed to be arisen. The $\alpha$-NiPtAl appeared as small precipitates in SEM observations. The $\gamma^{\prime}-(\mathrm{Ni}, \mathrm{Pt})_{3} \mathrm{Al}$ was detected with a lattice parameter of $0.3690 \mathrm{~nm}$ and also appeared as small precipitates (not easily distinguishable from $\alpha$ precipitates by SEM). The third identified phase was $\gamma$-(Pt,Ir) with a lattice parameter of $0.3685 \mathrm{~nm}$ and appeared in grey in the SEM pictures. This phase corresponded to the phase of the deposited Pt-25Ir layer but its lattice parameter decreased due to the inward Pt and Ir diffusion. The presence of the three phases after $1 \mathrm{~h}$ proved that Ir addition did not modify the local phase transformation sequence. This was also demonstrated with the EPMA analyses (Fig. 8). However, the Ir addition delayed the $\alpha$ phase formation which was observed after 15 min instead of $1 \mathrm{~min}$ in systems without Ir. Uphill Al diffusion was also less significant in Ir-systems than in Pt-systems. Moreover, Ir slows down the interdiffusion when compared with pure Pt (Fig. 8). The evolution of the interdiffusion zone thickness with time for Pt and Pt + Pt-25Ir coatings validates this idea despite the deviation in the measured thicknesses (Fig. 9). The interdiffusion zone thickness of Ir-free systems was higher in average from 10 to $30 \%$ to the one of the Ir system. For example after $60 \mathrm{~min}$, the interdiffusion zone thickness of the system without Ir was $12.4 \pm$ 

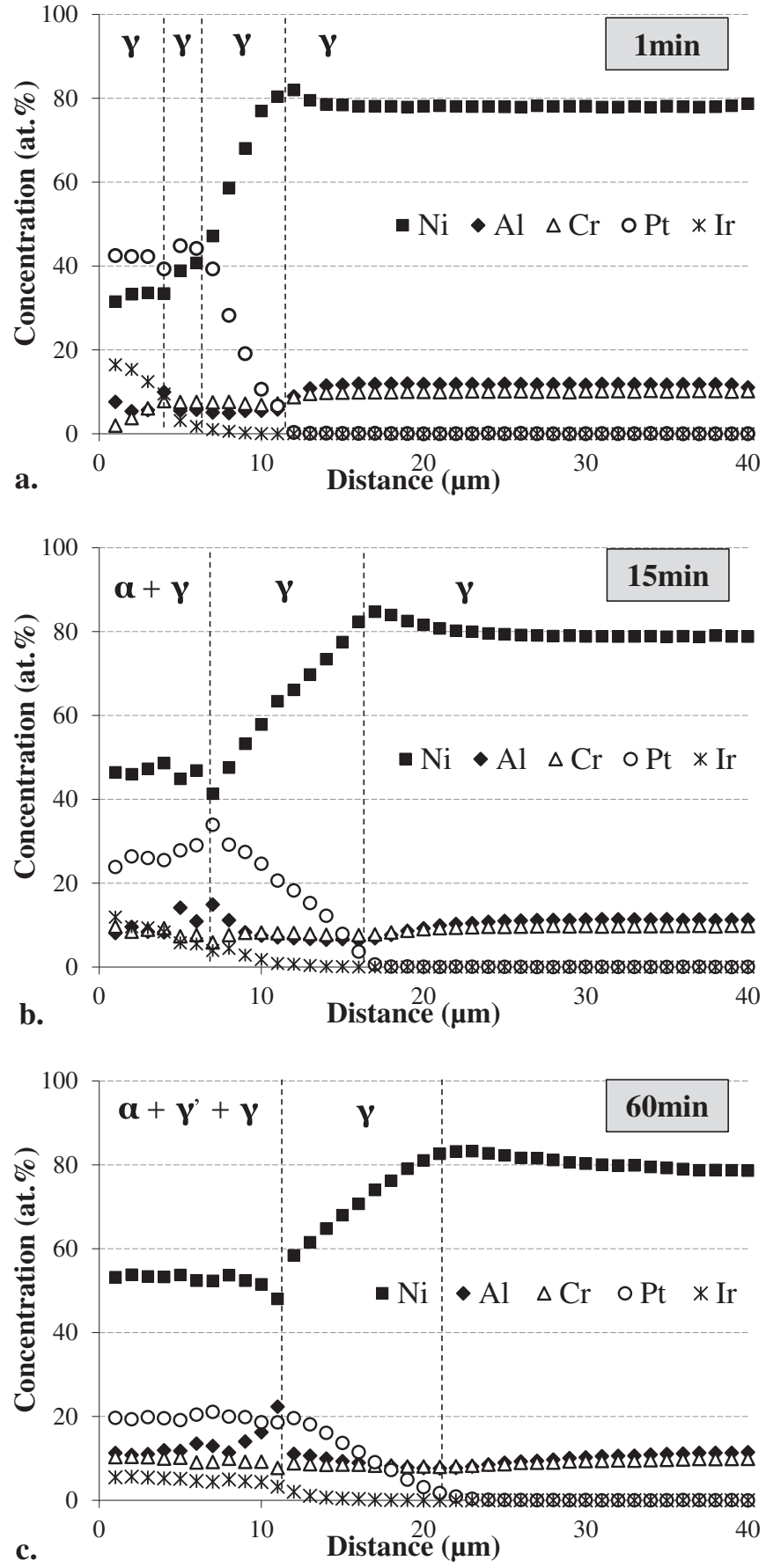

Fig. 8. EPMA concentration profiles ( 1 point every $1 \mu \mathrm{m}$ ) for the $\mathrm{Ni}-12 \mathrm{Al}-10 \mathrm{Cr} / \mathrm{Pt}+\mathrm{Pt}-25 \mathrm{Ir}$ system after (a) $1 \mathrm{~min}$, (b) $15 \mathrm{~min}$ and (c) $60 \mathrm{~min}$ at $1100{ }^{\circ} \mathrm{C}$ under argon.

$1.7 \mu \mathrm{m}$ whereas the one with Ir was $10.6 \pm 1.7 \mu \mathrm{m}$. Another remark concerns the Ir volatilization since pure Ir can form volatile oxide such as $\mathrm{IrO}_{3}$ between 800 and $1700 \mathrm{~K}$ [34]. An Ir volatilization of about 20 to $30 \%$ of what was deposited was calculated by integrating the Ir profiles after $1 \mathrm{~min}$ and $1 \mathrm{~h}$ at $1100{ }^{\circ} \mathrm{C}$. All of this implies that the substitution of 25 at.\% of Pt by Ir decreases the chemical interaction with Al when compared with a pure Pt coating. In other words, Ir decreases the Pt effect by dilution, or even gives an opposite contribution to the Pt one, and limits the Al flux toward the surface. This hypothesis is consistent with the fact that Ir partitions in the $\gamma$ phase with a stronger interaction with Ni while Pt partitions in the $\gamma^{\prime}$ phase. The superimposition of the $\mathrm{Al}$ profiles for both systems (with and without Ir) after 1 min at $1100{ }^{\circ} \mathrm{C}$ (Fig. 10.a) exhibits a similar evolution, i.e. a comparable valley. However, some

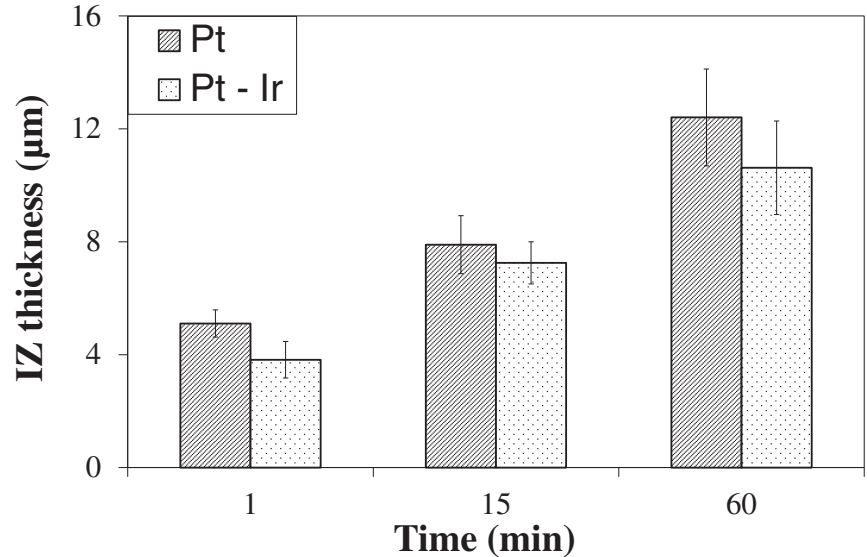

Fig. 9. Evolution of the interdiffusion zone (IZ) thickness with time for the Ni-12Al-10Cr/ electroplated-Pt and Pt + Pt-25Ir (at.\%) systems after annealing at $1100{ }^{\circ} \mathrm{C}$ under argon.

deviation appeared between the concentration gradients at the surface and at the interdiffusion zone/substrate interface. Moreover, Pt and $\mathrm{Pt}+\mathrm{Ir}$ profiles did not superimpose since 59 at.\% of Pt + Ir was found at the surface whereas 47 at.\% of Pt were detected in Ir-free systems despite the Ir volatilization (Fig. 10.b). Iridium diffuses less quickly toward the substrate than Pt which is consistent with the literature [26]. This also evidences a lower Pt + Ir flux toward the substrate. This lower inward Pt + Ir flux may decrease the outward vacancy flux and then, Ir may limit Kirkendall voids formation during interdiffusion.
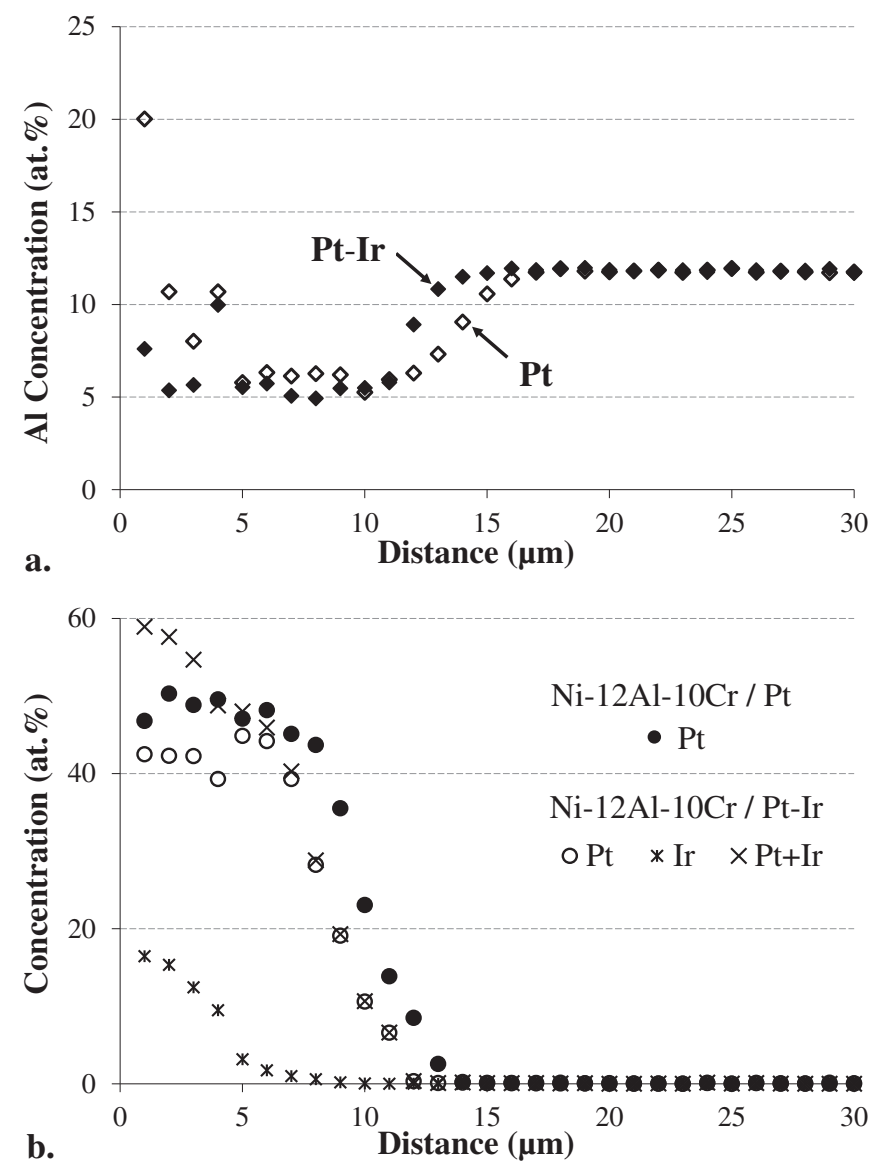

Fig. 10. Comparison of the concentration profiles of (a) aluminum and (b) platinum and iridium between the systems Ni-12Al-10Cr/Pt and Ni-12Al-10Cr/Pt + Pt-25Ir after $1 \mathrm{~min}$ at $1100{ }^{\circ} \mathrm{C}$ under argon. 
a.

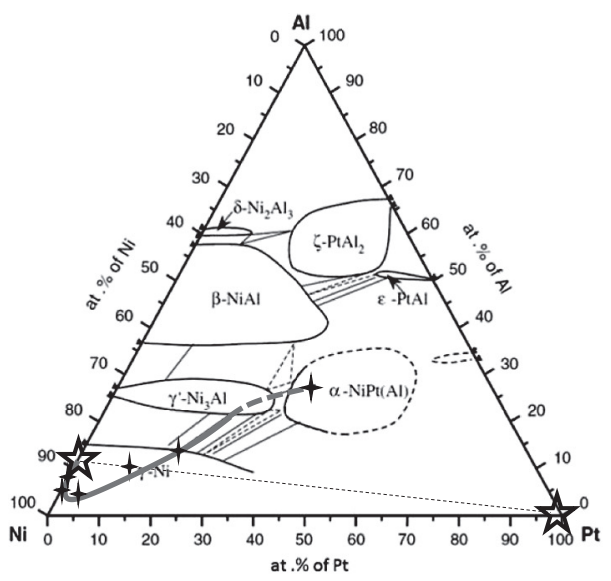

b.

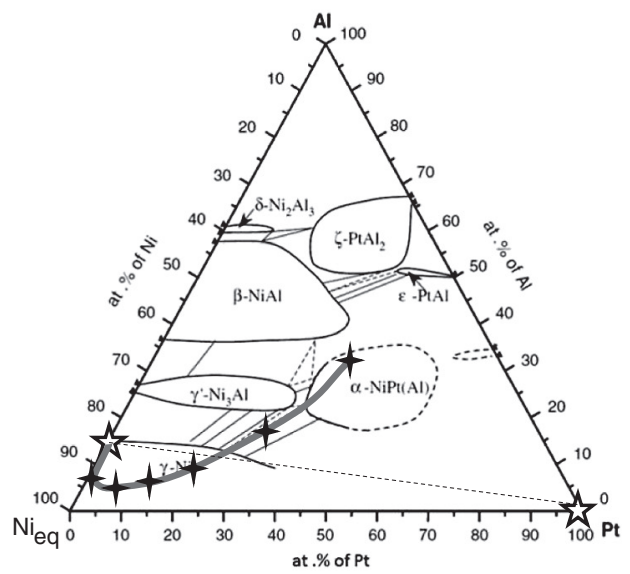

c.

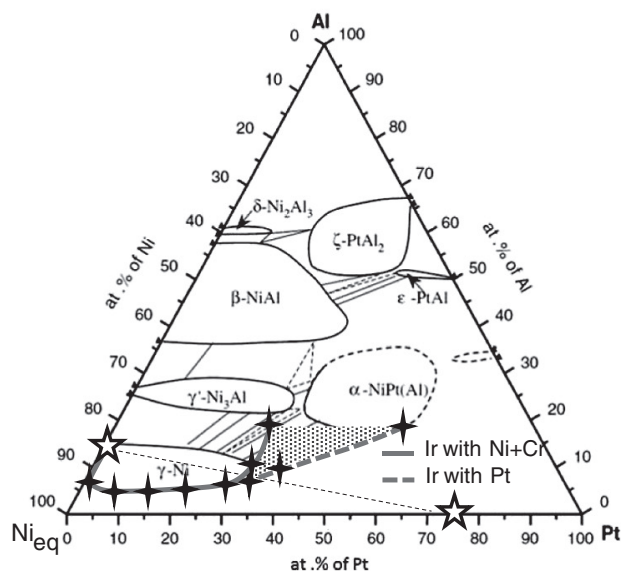

Fig. 11. Diffusion paths after $15 \mathrm{~min}$ at $1100^{\circ} \mathrm{C}$ under argon of three systems: (a) Ni-13Al/ Pt, (b) Ni-12Al-10Cr/Pt and (c) Ni-12Al-10Cr/Pt + Pt-25Ir. In the figures b and c, $\mathrm{Ni}_{\text {eq }}$ corresponds to the addition of the nickel and chromium contents. Stars correspond to the initial composition at $t_{0}$ and crosses correspond to experimental values after $15 \mathrm{~min}$. Continuous lines are known paths and dashed lines are speculated paths.

\subsection{Diffusion paths}

Fig. 11 exhibits the diffusion paths after $15 \mathrm{~min}$ at $1100{ }^{\circ} \mathrm{C}$ of the two systems (Ni-Al-Cr-Pt and Ni-Al-Cr-Pt-Ir) compared with the previously studied system (Ni-Al-Pt) [5] on the isothermal Ni-Al-Pt phase diagram $[3,35]$. Cr modifies the stability domain of the $\gamma^{\prime}$ phase as shown by Taylor and Floyd [36] but the diffusion paths were chosen to be represented in the same Ni-Al-Pt diagram. As $\mathrm{Cr}$ preferentially partitions in the $\gamma$ phase, its content was added to the one of Ni. Globally, the diffusion paths were approximatively similar in Ni-Al-Pt and Ni-Al-Cr-Pt diffusion couples. The extent of uphill diffusion of Al due to the thermodynamic effect of Pt allowed the ternary $\alpha$ phase formation. The uphill Al diffusion was so significant with the addition of a fourth element that $\beta$-(Ni,Pt)Al could have formed. $\mathrm{Cr}$ addition also allowed the crossing of the $\alpha / \gamma^{\prime} / \gamma$ ternary domain, this equilibrium being possible according to the Gibbs phase rule.

In order to represent the diffusion path of the Pt-Ir systems on the $\mathrm{Ni}$-Al-Pt diagram, the Ir concentration can be added to the Ni or Pt content since it preferentially partitions in the $\gamma$ phase or because it is a $\mathrm{Pt}$ group element. Both solutions were applied and an extended zone comprised between these two diffusion paths was represented for the Ircontaining system which was consistent with the XRD and SEM observations revealing the $\alpha / \gamma$ equilibrium. Regardless of this, a lower $\mathrm{Al}$ surface concentration was nevertheless observed when compared to the Ir-free system. In addition, the ternary domain could be crossed.

Finally, all these diffusion paths highlight the importance of the $\alpha$ NiPtAl phase and its aptitude to be used in TBC systems either as a precursor of the Pt-only $\gamma-\gamma^{\prime}$ bond-coatings [5] or as a bond-coating itself [37].

\section{Conclusion}

According to the preliminary study [5], a $5 \mu \mathrm{m}$ thick layer of Pt was deposited by electroplating on a $\gamma \mathrm{Ni}-12 \mathrm{Al}-10 \mathrm{Cr}$ model alloy in order to study the $\mathrm{Cr}$ effect on the interdiffusion. Similarly, $2 \mu \mathrm{m}$ of Pt and $3 \mu \mathrm{m}$ of Pt-25Ir were deposited on the same alloy to investigate the Ir effect. After fabrication, interdiffusion treatments for $1 \mathrm{~min}$ up to $1 \mathrm{~h}$ at $1100{ }^{\circ} \mathrm{C}$ under argon were performed. The main results can be summarized as follows:

- $\mathrm{Cr}$ addition increases the uphill diffusion of Al to the surface,

- $\mathrm{Al}$ and $\mathrm{Cr}$ have a positive chemical interaction in presence of $\mathrm{Pt}$,

- Pt has a negative chemical interaction with $\mathrm{Al}$ and with $\mathrm{Cr}$ in such a way that Pt decreases their activities. According to the diffusion coefficient values, Pt has a greater influence on the Al activity than on the Cr one.

- Ir slows down the diffusion when compared with systems with Pt only. As a consequence, Ir may reduce Kirkendall voids formation during interdiffusion.

- Ir decreases the Pt effect on Al activity by dilution. Therefore, the uphill diffusion of $\mathrm{Al}$ was reduced and the $\alpha$ phase formation was delayed.

\section{Acknowledgements}

This study was performed with the financial support of SAFRAN Aircraft Engines (France) and NIMS (Japan). The authors would like to acknowledge Mr. Hiromichi Murakami at NIMS for fabrication of electroplated samples, and NIMS Materials Analysis Station for EPMA analysis.

\section{References}

[1] S. Bose, J. DeMasi-Marcin, Thermal barrier coating experience in gas turbine Engines at Pratt \& Whitney, J. Therm. Spray Technol. 6 (1) (1997) 99-104.

[2] K. Bouhanek, O.A. Adesanya, F.H. Stott, P. Skeldon, D.G. Lees, G.C. Wood, High temperature oxidation of thermal barrier coating systems on RR3000 substrates: Pt aluminide bond coats, Mater. Sci. Forum 639 (2001) 369.

[3] B. Gleeson, W. Wang, S. Hayashi, D. Sordelet, Effects of platinum on the interdiffusion and oxidation behavior of Ni-Al-based alloys, Mater. Sci. Forum 461-464 (2004) 213-222.

[4] J.A. Haynes, B.A. Pint, Y. Zhang, I.G. Wright, Comparison of the cyclic oxidation behavior of $\beta$-NiAl, $\beta$-NiPtAl and $\gamma-\gamma^{\prime}$ NiPtAl coatings on various superalloys, Surf. Coat. Technol. 202 (2007) 730.

[5] P. Audigié, A. Rouaix-Vande Put, A. Malié, P. Bilhé, S. Hamadi, D. Monceau, Observation and modeling of alpha-NiPtAl and Kirkendall void formations during interdiffusion of a Pt coating with a gamma-(Ni-13Al) alloy at high temperature, Surf. Coat. Technol. 260 (2014) 9-16.

[6] C.T. Sims, N.S. Stoloff, W.C. Hagel, Superalloys II (Extrait), Wiley-Interscience, 1987 640. 
[7] M.C. Pessah-Simonetti, Role and behaviour of the $\mu$ phase during deformation of a nickel-based single crystal superalloy, Mater. Sci. Eng. A254 (1998) 1-12.

[8] P. Kuppusami, H. Murakami, A comparative study of cyclic oxidized Ir aluminide and aluminized nickel base single crystal superalloy, Surf. Coat. Technol. 186 (3) (2004) 377-388.

[9] M. Durand-Charre, The Microstructure of Superalloys, Gordon and Breach Science Publishers, 1997124

[10] G.H. Meier, F.S. Pettit, High-temperature corrosion of alumina-forming coatings for superalloys, Surf. Coat. Technol. 39-40 (1989) 1-17.

[11] C.S. Giggins, F.S. Pettit, Oxidation of Ni-Cr-Al alloys between $1000^{\circ}$ and $1200{ }^{\circ} \mathrm{C}$, J. Electrochem. Soc. 118 (11) (1971) 1782-1790.

[12] D.J. Young, High Temperature Oxidation and Corrosion of Metals, in: T. Burnstein (Ed.), Elsevier Corrosion Series, Elsevier, Amsterdam, 2008.

[13] J.A. Nesbitt, R.W. Heckel, Predicting diffusion paths and Interface motion in $\gamma / \gamma+\beta$, $\mathrm{Ni}-\mathrm{Cr}-\mathrm{Al}$ diffusion couples, Metall. Trans. A 18A (1987) 2087-2094.

[14] S. Hayashi, W. Wang, D.J. Sordelet, B. Gleeson, Interdiffusion behavior of Pt-modified gamma-Ni + gamma-Ni3Al alloys coupled to Ni-Al-based alloys, Metall. Mater. Trans. Phys. Metall. Mater. Sci. 36A (7) (2005) 1769-1775.

[15] F. Wu, H. Murakami, A. Suzuki, Development of an iridium-tantalum modified aluminide coating as a diffusion barrier on nickel-base single crystal superalloy TMS-75, Surf. Coat. Technol. 168 (1) (2003) 62-69.

[16] F. Wu, H. Murakami, H. Harada, Cyclic oxidation behavior of iridium-modified aluminide coatings for nickel-base single crystal superalloy TMS-75, Mater. Trans. 44 (9) (2003) 1675-1678.

[17] R. Swadźba, M. Hetmańczyk, M. Sozanska, B. Witala, L. Swadźba, Structure and cyclic oxidation resistance of Pt, Pt/Pd-modified and simple aluminide coatings on CMSX4 superalloy, Surf. Coat. Technol. 206 (2011) 1538-1544.

[18] S. Alpérine, P. Steinmetz, P. Josso, A. Constantini, High temperature-resistant palladium-modified aluminide coatings foir nickel-base superalloys, Mater. Sci. Eng. A 121 (1989) 367-372.

[19] S. Alpérine, P. Steinmetz, A. Constantini, P. Josso, Structure and high temperature performance of various palladium-modified aluminide coatings: a low cost alternative to platinum aluminides, Surf. Coat. Technol. 43/44 (1) (1990) 347-358.

[20] P. Lamesle, Revêtements d'aluminiures modifiés par le palladium:mécanismes de formation et comportement en oxydation/corrosion à haute température, Université Henri Poincaré, 1995.

[21] R. Swadźba, M. Hetmańczyk, J. Wiedermann, L. Swadźba, G. Moskal, B. Witala, K. Radwanski, Microstructure degradation of simple, Pt and Pt + Pd-modified aluminide coatings on CMSX-4 superalloy under cyclic oxidation conditions, Surf. Coat. Technol. 2015 (2013) 16-23.

[22] H. Hosoda, T. Takahashi, M. Takehara, T. Kingetsu, H. Masumoto, Phase stability and mechanical properties of IrAl alloys, Mater. Trans. JIM 38 (10) (1997) 871-878.
[23] J. Merker, D. Lupton, M. Töpfer, H. Knake, High temperature mechanical properties of the platinum group metals, Platin. Met. Rev. 45 (2) (2001) 74-82.

[24] H. Murakami, Y. Koizumi, T. Yokokawa, Y. Yamabe-Mitarai, T. Yamagata, H. Harada, Atom-probe microanalysis of Ir-bearing Ni-Base superalloys, Mater. Sci. Eng. A250 (A250) (1998) 109-114.

[25] H. Murakami, T. Honma, Y. Koizumi, H. Harada, E.b.T.M.P.e. al. (Ed.), Distribution of Platinum Group Metals in Ni-base single-Crystal Superalloys, in Superalloys, Editor. 2000 (2000) 747-756.

[26] M.S.A. Karunaratne, R.C. Reed, Interdiffusion of the platinum-group metals in nickel at elevated temperatures, Acta Mater. 51 (10) (2003) 2905-2919.

[27] H. Murakami, Y. Matsumura, K. Kasai, A. Sato, A. Tateno, H. Yoshizawa, K. Noba, Effect of Ir addition to Pt-based oxidation resistant coatings, High Temperature Corrosion and Protection of Materials, 2012 Les Embiez (France).

[28] M. Boidot, Elaboration de revêtements $\gamma$ - $\gamma^{\prime}$ et de systèmes barrière thermique par Spark Plasma Sintering, Institut National Polytechnique de Toulouse, Thèse, 2010.

[29] P. Audigié, Modélisation de l'interdiffusion et du comportement en oxydation cyclique de superalliages monocristallins à base de nickel revêtus d'une souscouche $\gamma-\gamma$ ' riche en platine. Extension aux systèmes barrière thermique, Institut National Polytechnique de Toulouse, Thèse, 2015.

[30] R.A. Swalin, A. Martin, Solute diffusion in nickel-base substitutional solid solutions, J. Metals 8 (1956) 567-572.

[31] Y. Minamino, H. Yoshida, S.B. Jung, K. Hirao, T. Yamane, Diffusion of Platinum and Molybdenum in Ni and Ni3Al, 143-147, 1997 257-262.

[32] J.A. Nesbitt, R.W. Heckel, Interdiffusion in Ni-rich, Ni-Cr-Al alloys at 1100 and $1200^{\circ} \mathrm{C}$ : part II. Diffusion coefficients and predicted concentration profiles, Metall. Trans. A 18A (1987) 2075-2086.

[33] J.A. Nesbitt, R.W. Heckel, Interdiffusion in Ni-rich, Ni-Cr-Al alloys at 1100 and $1200{ }^{\circ} \mathrm{C}$ : part I. Diffusion paths and microstructures, Metall. Trans. A 18A (1987) 2061-2073.

[34] M. Asadian, Modern aspects of bulk crystal and thin film preparation, in: N. Kolesnikov, E. Borisenko (Eds.), The Influence of Atmosphere on Oxides Crystal Growth, Chapter 6, InTech, 2012.

[35] S. Hayashi, S.I. Ford, D.J. Young, D.J. Sordelet, M.F. Besser, B. Gleeson, Alpha-NiPt(Al) and phase equilibria in the Ni-Al-Pt system at $1150{ }^{\circ} \mathrm{C}$, Acta Mater. 53 (11) (2005) 3319-3328.

[36] A. Taylor, R.W. Floyd, The constitution of nickel-rich alloys of the Ni-Al-Cr system, J. Inst. Metal. 81 (1952) 451-464.

[37] M. Carlin, Design, Manufacture and High Temperature Behaviour of a-Phase Bondcoat for Thermal Barrier Coating, Ph.D. School of Applied Sciences, 2007. 